NASA Technical Memorandum 107739

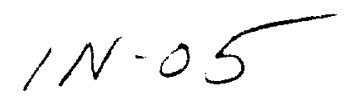

$16029 \%$

\title{
SUPERSONIC AEROELASTIC INSTABILITY RESULTS FOR A NASP-LIKE WING MODEL
}

Stanley R. Cole

James R. Florance

Lee B. Thomason

Charles V. Spain

Ellen P. Bullock

April 1993

(NASA-TM-107739) SUPERSONIC

AEROELASTIC INSTABILITY RESULTS FOR

A NASP-LIKE WING MODEL (NASA)

$12 \mathrm{p}$
N93-26553

Unclas

$03 / 05$

National Aeronautics and

Space Administration

Langley Research Center

Hampton, Virginia 23681-0001 



\title{
SUPERSONIC AEROELASTIC INSTABILITY RESULTS FOR A NASP-LIKE WING MODEL
}

\author{
Stanley R. Cole \\ James R. Florance \\ Lee B. Thomason \\ NASA Langley Research Center \\ Hampton, VA 23681-0001 \\ Charles V. Spain \\ Ellen P. Bullock \\ Lockheed Engineering and Sciences Company \\ Hampton, VA 23666
}

\begin{abstract}
An experimental study and an analytical study have been conducted to examine static divergence for hypersonic-vehicle wing models at supersonic conditions. A supersonic test in the Langley Unitary Plan Wind Tunnel facility was conducted for two wind-tunnel models. These models were nearly identical with the exception of airfoil shape. One model had a four-percent maximum thickness airfoil and the other model had an eight-percent maximum thickness airfoil. The wing models had lowaspect ratios and highly swept leading edges. The allmovable wing models were supported by a single-pivot mechanism along the wing root. For both of the windtunnel models, configuration changes could be made in the wing-pivot location along the wing root and in the wingpivot pitch stiffness. Three divergence conditions were measured for the four-percent thick airfoil model in the Mach number range of 2.6 to 3.6 and one divergence condition was measured for the eight-percent thick airfoil model at a Mach number of 2.9. Analytical divergence calculations were made for comparison with experimental results and to evaluate the parametric effects of wing-pivor stiffness, wing-pivot location, and airfoil thickness variations. These analyses showed that decreasing airfoil thickness, moving the wing-pivot location upstream, or increasing the pitch-pivot stiffness have the beneficial effect of increasing the divergence dynamic pressures. The calculations predicted the trend of experimental divergence dynamic pressure with Mach number accurately; however, the calculations were approximately 25 percent conservative with respect to dynamic pressure.
\end{abstract}

\section{NOMENCLATURE}

c local wing chord, in

c wing-root chord, in

f frequency, $\mathrm{Hz}$

M Mach number

q dynamic pressure, $1 \mathrm{~b} / \mathrm{ft}^{2}$

q measured divergence $q, 1 b / \mathrm{ft}^{2}$

q extrapolated experimental divergence $q, \mathrm{lb}_{\mathrm{t}} \mathrm{ft}^{2}$

$t$ local wing thickness, in

$t_{8}$ pitch-stiffness element thickness, in

$x$ streamwise distance from wing root leading edge, in

$\alpha$ angle of attack, degrees

$\rho$ fluid density, $\mathrm{lb} \cdot \sec ^{2} / \mathrm{in}^{4}$

$\zeta$ damping

\section{Subscripts:}

a analytical result

m measured result

\section{INTRODUCTION}

A major technological feasibility study has been underway in the United States in recent years to develop a reusable hypersonic space vehicle, referred to as the National Aero-Space Plane (NASP). The NASP, or X30 , vehicle is designed to take-off and land as a conventional airplane and yet be capable of attaining hypersonic speeds and orbital altitudes. An artist conception of the proposed NASP vehicle is shown in figure 1. In early planning for the NASP technological feasibility study, one discipline that was characterized as needing special attention for such a unique vehicle concept was aeroelasticity. As a result a number of experimental studies were initiated by the NASP Joint Program Office 
to study various aeroelastic aspects of the NASP vehicle in the subsonic, transonic, supersonic, and hypersonic speed regimes. Reference 1 summarizes the experimental studies that were initiated dealing with aeroelastic instabilities for the NASP wing and vertical fin surfaces.

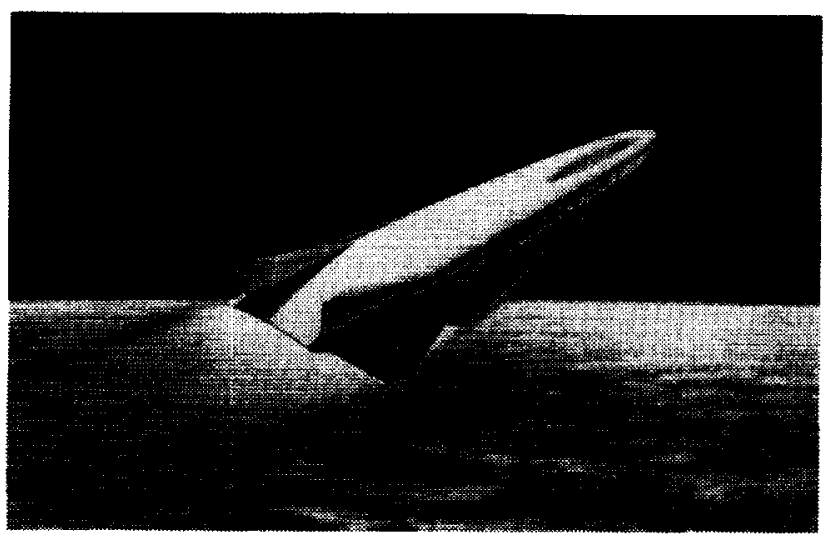

Fig. 1: Artist conception of the NASP.

One area that was identified as requiring further study was the aeroelastic behavior of a NASP-like wing at supersonic conditions. While the problems of transonic aeroelastic instabilities are well known, one study from the early 1960 's indicated the possibility of a second minimum instability speed in the hypersonic speed range. ${ }^{2}$ Such possibilities emphasize the need to better understand aeroelastic behavior of NASP-like vehicles throughout their flight envelope including the supersonic regime. Figure 2 shows results from aeroelastic analyses for the NASP vehicle design concept and sheds additional light on the need to conduct supersonic aeroelastic studies. The calculations shown in figure 2 are from reference 3. The figure shows two types of aeroelastic instabilities that were predicted for the NASP vehicle. The dynamic instabilities are labeled in the figure as body-freedom flutter and as wing/fuselage bending flutter. Both of these instabilities are highly influenced by the susceptibility of the wing to static divergence when isolated from the influence of the fuselage structure and aerodynamics. Other studies have shown that body-freedom flutter instabilities display themselves as static divergence if the wing is isolated from the influence of the fuselage. References 4 and 5 present results from one series of experimental and analytical studies that provide insight into the relationship between body-freedom flutter and static wing divergence.

A calculated instability boundary for such a wingalone static divergence phenomena for the NASP-vehicle design concept is also shown in figure 2. In order to gain some understanding of the aeroelastic behavior of a NASP-like vehicle it was decided to build wing-alone wind-tunnel models and test them in a supersonic facility. These wind-tunnel models, which were tested in the NASA Langley Unitary Plan Wind Tunnel facility, are the subject of this paper. They were designed for the purpose of obtaining information on the static divergence behavior of such configurations and to provide a data base for correlation with supersonic analytical predictions. Through the relationship between body-freedom flutter and static wing divergence, it was believed that results from these tests could be used to evaluate the validity of analyses techniques that would be used for the NASP vehicle. Analytical and experimental supersonic divergence results for the NASP-like wing models are presented in this paper.

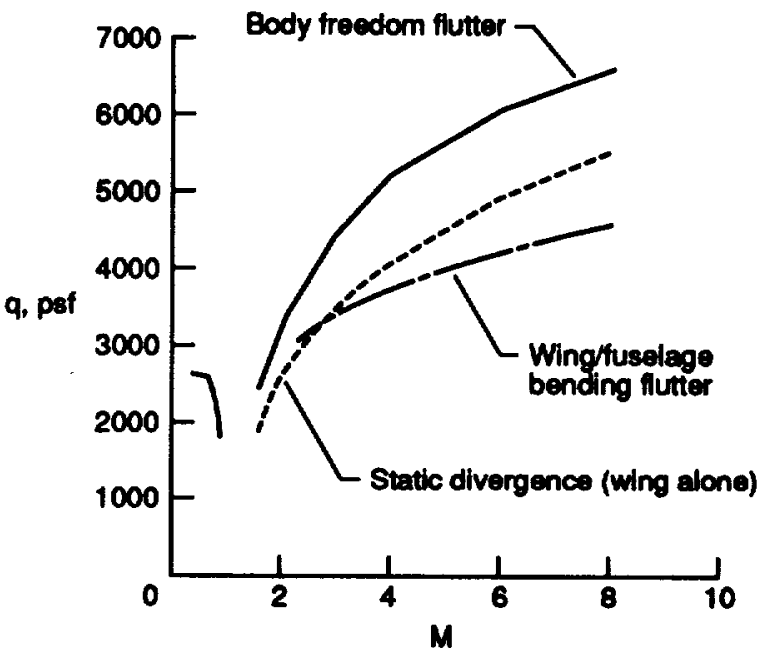

Fig. 2: Calculated instability boundaries for the NASP flight-vehicle design.

\section{MODELS}

The NASP-like wind-tunnel model was geometrically scaled from the NASP-vehicle design concept. Analysis of the full-scale NASP-vehicle concept without the fuselage was used to determine that the basic aeroelastic phenomena was a static wing divergence for a wing-alone configuration. Based on these full-scale analyses, an attempt was made to design an aeroelastically scaled windtunnel model. However, the combination of small size and low weight made this effort difficult. Furthermore, extreme static and dynamic loading that was anticipated during the supersonic start-up process in the wind-tunnel facility would have made building an aeroelastically-scaled model prohibitive with respect to both development time and budget. Instead, an attempt was made to construct a flexible model with conventional materials that would be geometrically similar to the NASP-vehicle wing design and that could withstand severe start-up loads. The wing model was designed to be mounted on a pivot as with the NASP-vehicle design and a pitch-stiffness element was attached to the pivot mechanism to simulate the wingpositioning actuator of the design vehicle. In this manner, a model design was developed which was predicted to have static divergence behavior very similar to 
that calculated for the NASP-vehicle design concept wing and within the operating capabilities of the wind-tunnel facility.

The supersonic divergence for both the NASP-vehicle design model and the wind-tunnel model was predicted to be primarily dependent on the first wing-pitch mode. Two characteristics of the wing had a major influence on this first wing-pitch mode. The first was the pitching moment provided through the pivot mechanism and the second was the streamwise flexibility of the wing. Supersonically, the influence of this second characteristic was a requirement for divergence because the location of the aerodynamic center at supersonic speeds was downstream of the pivot location for the vehicle design. Therefore the wing would be statically stable and would not diverge for any pitch-pivot stiffness. However, wing deformations in the first wing-pivot mode cause the aerodynamic center to shift forward and are a major contributing factor to the divergence predicted for the NASP-vehicle design concept. Although it was difficult to design a flexible wing that could withstand the start-up loads, enough flexibility was retained to allow the streamwise bending of the wing model that would lead to divergence. Since the divergence mode predicted for the wind-tunnel model was similar to that predicted for the NASP-vehicle design, the primary anticipated benefit of this study was to obtain an experimental database of this phenomena for correlation with analytical methodologies. These same methodologies could then be used with greater confidence to help ensure that the NASP-vehicle design was free of predictable aeroelastic instabilities.

Model geometry.- A planform drawing showing the basic structure of the wind-tunnel models is shown in figure 3. The wings had a root chord of $28.0^{\prime \prime}$ and a span of $9.86^{\prime \prime}$ with a $70^{\circ}$ leading-edge sweep and a $15^{\circ}$ trailingedge sweep. The wing airfoil is symmetric top to bottom and is formed by four intersecting arcs with the maximum thickness at $x / c=0.65$. Two wing models were constructed; one with a $t / c=0.04$ maximum airfoil thickness and a second model with a $t / c=0.08$ maximum airfoil thickness. The design airfoil shapes are specified in Table 1. A planform photograph of one of the wing models is shown in figure 4.

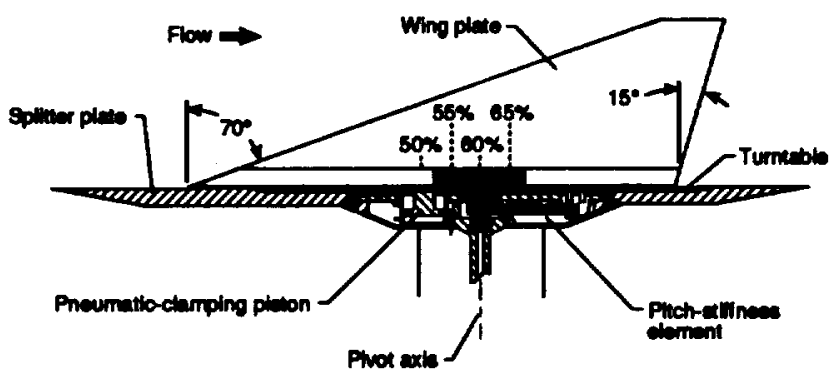

Fig. 3: Drawing of model and splitter plate apparatus.
The structural wing plate was identical for both models. The wing structure was a tapered aluminum plate with balsa wood attached to the upper and lower surfaces to provide the airfoil shape. For the first 10.1 percent of the wing semi-span (1"), the wing plate thickness was $0.2^{n}$ from the leading edge to $x / c_{r}=0.41$ and from $x / c_{r}=$ 0.74 to the trailing edge (with the exception of the leading-edge and trailing-edge tapers to meet the airfoil shape). The wing plate in this root area stepped to $0.3^{n}$ between $x / c_{r}=0.41$ and $x / c_{r}=0.74$. This raised midsection of the wing root area was used to attach the wing to the pivot mechanism. To attach the wing to the pivot mechanism, the wing was positioned and bolted into a steel bracket that was an integral part of the pivot mechanism. From the 10.1 percent semi-span to the wing tip, the wing plate was a constant thickness in the chordwise direction. In the spanwise direction, the wing plate tapered from $0.2^{n}$ thick to $0.025^{n}$ thick at the wing tip.

Table 1: Design airfoil coordinates.

\begin{tabular}{|c|c|c|}
\hline$x / c$ & $\begin{array}{c}t / c \\
\text { (four-percent } \\
\text { airfoil model) }\end{array}$ & $\begin{array}{c}t / c \\
\text { (eight-percent } \\
\text { airfoil model) }\end{array}$ \\
\hline & & \\
\hline 0.00 & 0.0000 & 0.0000 \\
\hline 0.05 & 0.0059 & 0.0118 \\
\hline 0.10 & 0.0114 & 0.0228 \\
\hline 0.15 & 0.0163 & 0.0326 \\
\hline 0.20 & 0.0208 & 0.0416 \\
\hline 0.25 & 0.0249 & 0.0498 \\
\hline 0.30 & 0.0284 & 0.0568 \\
\hline 0.35 & 0.0315 & 0.0630 \\
\hline 0.40 & 0.0341 & 0.0682 \\
\hline 0.45 & 0.0362 & 0.0724 \\
\hline 0.50 & 0.0379 & 0.0758 \\
\hline 0.55 & 0.0391 & 0.0782 \\
\hline 0.60 & 0.0398 & 0.0796 \\
\hline 0.65 & 0.0400 & 0.0800 \\
\hline 0.70 & 0.0392 & 0.0784 \\
\hline 0.75 & 0.0367 & 0.0734 \\
\hline 0.80 & 0.0327 & 0.0654 \\
\hline 0.85 & 0.0270 & 0.0540 \\
\hline 0.90 & 0.0196 & 0.0392 \\
\hline 0.95 & 0.0106 & 0.0212 \\
\hline 1.00 & 0.0000 & 0.0000 \\
\hline & & \\
\hline
\end{tabular}

Pivot mechanism.- A pivot mechanism was designed into the model splitter plate apparatus to physically support the wing model and to simulate the pitch degree of freedom as planned for the NASP-vehicle design concept. The pivot mechanism and the pitch axis for the wing are shown in figure 3 . This pivot mechanism consisted of a steel cylinder mounted on ball bearings in 
the splituer plate with a steel-bracket clamp (to which the wing model was attached) integrally built onto the cylindrical section. Four pitch-axis-location configurations were available for the models. These configurations were selected by positioning the wing model within the support bracket so that the pitch axis was located at $x / c_{r}=0.50,0.55,0.60$, or 0.65 . A multiple-exposure photograph of the model pivoted to three different angles of attack is shown in figure 5. An all-movable wing concept very similar in construction to these models has been previously tested at supersonic conditions and is reported in reference 6.

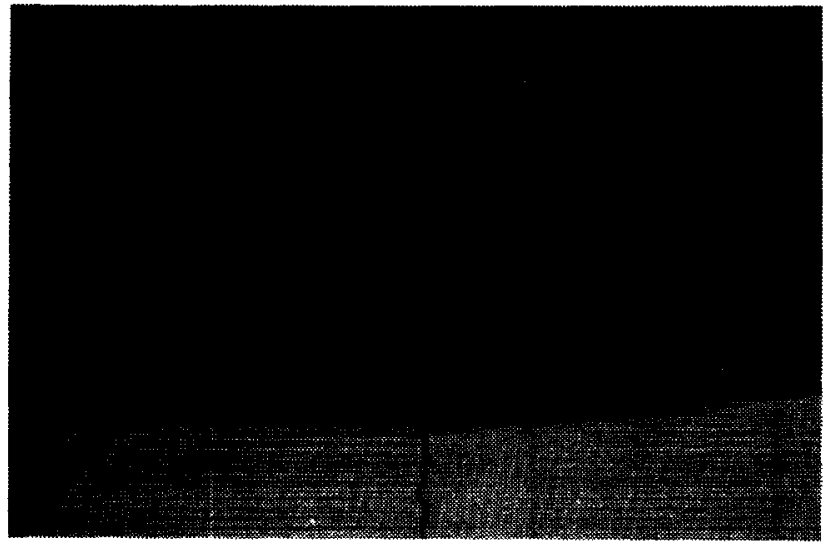

Fig. 4: Photograph of eight-percent thick airfoil model.

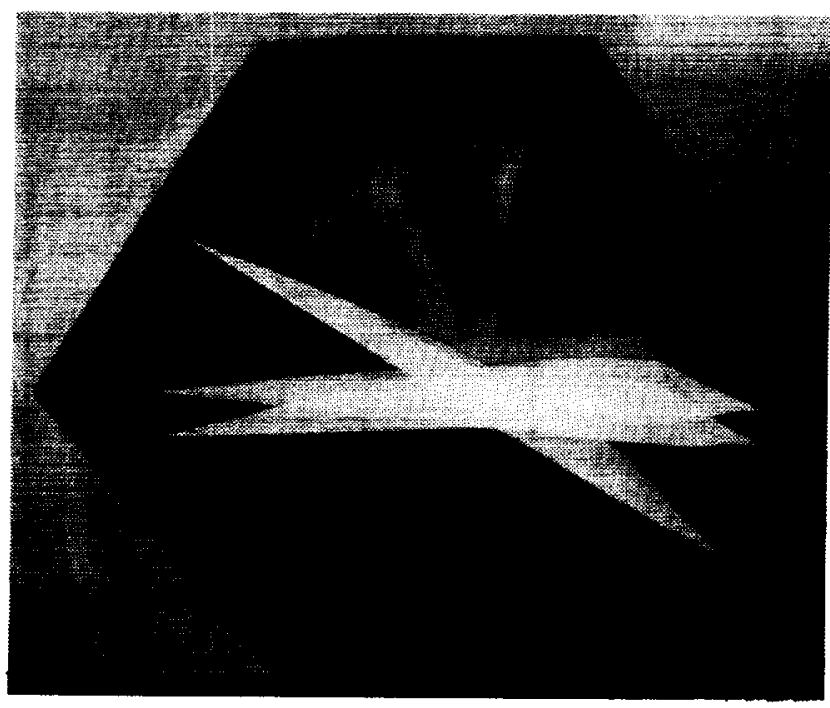

Fig. 5: Multiple-exposure photograph of model assembly.

Stiffness elements.- The wing model was unconstrained to pitch on the pivot mechanism itself. To provide the pitch stiffness of the model, pitch-stiffness elements were attached between the pivot mechanism and the angle-of-attack turntable that was built into the splitter plate. A drawing of these elements is shown is figure 6 . The pitch-stiffness element was cantilever-mounted to the wing pivot mechanism and was pivot-mounted to the turntable via a rod-and-slot support as shown in figures 3 and 6. Four different pitch-stiffness element configurations were available for the supersonic windtunnel test. These elements varied only in their thicknesses $\left(t_{g}=0.250^{\prime \prime}, 0.125^{\prime \prime}, 0.063^{\prime \prime}\right.$, and $\left.0.031^{\prime \prime}\right)$. For clarity throughout this paper, the pitch-stiffness element with $t_{s}=0.125^{\prime \prime}$ will be referred to as the nominal stiffness configuration and the pitch-stiffness element with $t_{s}=0.063^{\prime \prime}$ will be referred to as the soft stiffness configuration. A photograph of the four pitch-stiffness elements prior to the slotting of the pivot-rod supported end is shown in figure 7.

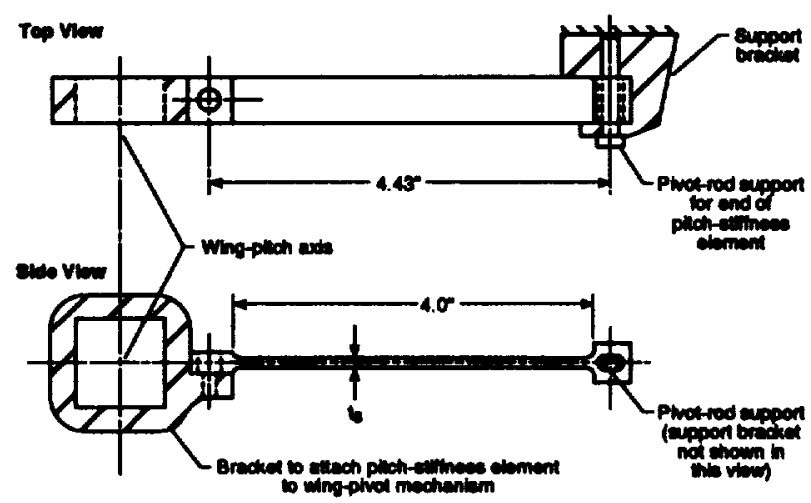

Fig. 6: Drawing of pitch-stiffness element.

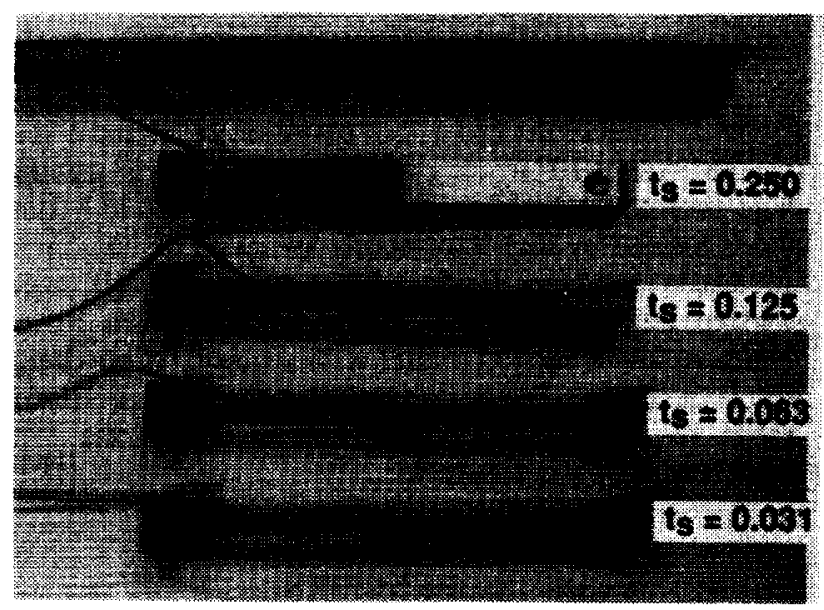

Fig. 7: Photograph of pitch-stiffness elements.

Safety feature.- A special safety feature was built into the pivot mechanism and pitch-stiffness element arrangement so that pitch-stiffness element deflections were mechanically limited in the event of an actual divergence instability. With this safety feature, the wing model could not attain angle of attack excursions on the pivot mechanism as large as shown in figure 5 unless a structural failure of the model occurred. This feature was used to actually obtain two hard divergence instabilities 
during the supersonic test without sustaining damage to the model.

Instrumentation.- The wind-tunnel model was instrumented with three bending strain-gauge bridges for measuring static and dynamic loading. One of these bridges was mounted on each pitch-stiffness element to provide static pitching moment and wing-pitching dynamics at the pitch pivot. The two other bridges were mounted on the wing plate and oriented to measure either spanwise or chordwise bending of the wing. Measurements from these strain-gauge bridges were monitored during wind-tunnel testing with a strip chart recorder, a frequency analyzer, and a computer terminal driven by the wind-tunnel facility data acquisition system. In addition to the instrumentation on the model, an angleof-attack accelerometer was mounted on the turntable inside the splitter plate housing (figure 8). This accelerometer indicated the preset angle of attack of the model. Pressure probes were also used between the splitter plate apparatus and test section wall to verify that the flow around the model was supersonic.

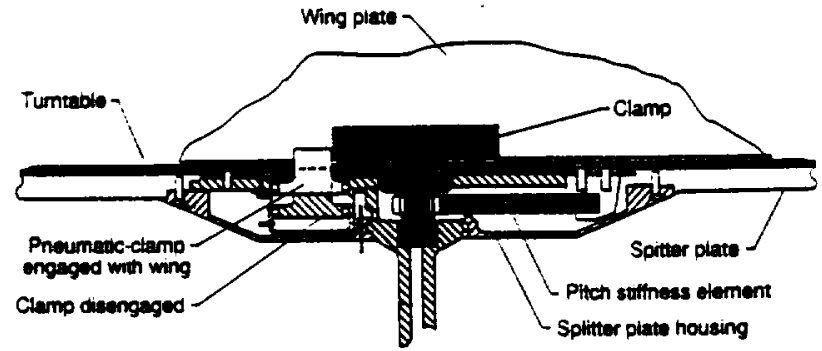

Fig. 8: Drawing of splitter plate housing and internal mechanisms.

Vibration characteristics.- Structural dynamic analyses were conducted for the wind-tunnel model using the Engineering Analysis Language (EAL) finite-elementprogram package ${ }^{7}$. Two-dimensional plate elements were used to simulate the structural properties of the aluminum plate in the model. A drawing of the finite element model is shown in figure 9. The wing plate was assembled as two-dimensional plate elements with thicknesses that approximate the local wing plate thickness. Collocated with these wing-plate elements were similar twodimensional elements that simulate an idealized stiffness and mass for the balsa-wood airfoil. The steel bracket that supports the wing at the pivot was simulated with Ushaped beam finite elements. The remainder of the pivot mechanism was simulated as a rigid tube finite element with one rotational degree of freedom to match the pitch rotational constraint imposed on the physical model. Rectangular beam finite elements were attached to the rigid tube of the pivot mechanism to approximate the model pitch-stiffness element. EAL was used to calculate natural frequencies, mode shapes, and generalized mass properties for the wind-tunnel models.

Vibration characteristics of the wind-tunnel models were also determined experimentally for many of the pitch-stiffness and pivot-location variations. This was accomplished by exciting the first several vibration modes of the model, one at the time, with a sinusoidal excitation from an electromagnetic shaker. While dwelling on a natural frequency of the model, an external accelerometer was used to measure the natural frequency and to locate the node lines of the vibration mode shape. Measured and calculated frequencies and node lines for four of the primary vibrational modes are shown in figure 10 for a four-percent airfoil model configuration. Table 2 shows measured and calculated frequencies for the two windtunnel model configurations for which experimental divergence conditions were determined.

Table 2: Measured and calculated frequencies for fourpercent airfoil model with pivot at $x / c_{2}=0.65$.

\begin{tabular}{|c|c|c|c|c|}
\hline \multirow{2}{*}{ Mode } & \multicolumn{2}{|c|}{ Nominal } & \multicolumn{2}{c|}{ Soft } \\
\cline { 2 - 5 } & $\mathrm{f}_{\mathrm{m}}$ & $\mathrm{f}_{\mathrm{a}}$ & $\mathrm{f}_{\mathrm{m}}$ & $\mathrm{f}_{\mathrm{a}}$ \\
\hline & & & & \\
\hline 1 & 9.1 & 8.1 & 3.1 & 3.2 \\
\hline 2 & 52 & 49 & 52 & 49 \\
\hline 3 & 102 & 100 & 102 & 100 \\
\hline 4 & 144 & 138 & 146 & 138 \\
\hline
\end{tabular}

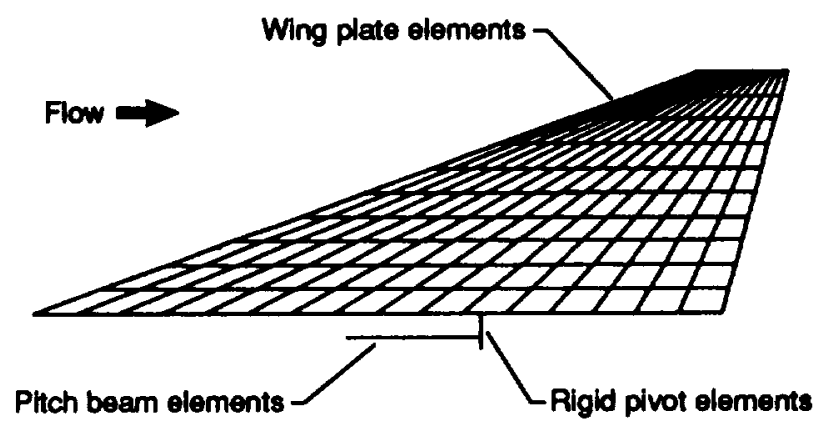

Fig. 9: Drawing of EAL finite element model.

\section{DIVERGENCE EXPERIMENTS}

\section{Wind Tunnel}

The supersonic testing of the NASP-like wing model was accomplished in the NASA Langley Unitary Plan Wind Tunnel (UPWT) facility. 8 The UPWT facility consists of two separate test sections. The cross section of both test sections is $4.0 \mathrm{ft}$. square. One test section (test section 1) is capable of variable pressure testing across the Mach number range of $\mathrm{M}=1.5$ to $\mathrm{M}=2.8$. 
Test section 2 is also capable of variable pressure testing across the Mach number range of $M=2.3$ to $M=4.6$. The operational Mach number ranges of each test section are further divided according to the combination of drive compressors that must be operated to obtain the desired test conditions. This experiment was conducted in test section 2 and utilized two of the three compressor modes available in test section 2 . These two compressor modes cover a range of Mach number from $\mathbf{M}=2.3$ to $\mathbf{M}=3.7$. The test medium in the UPWT is air.

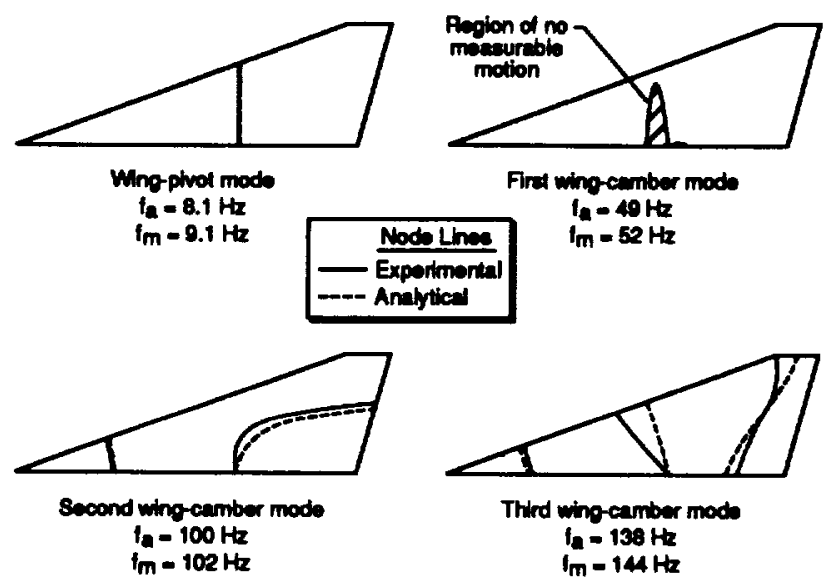

Fig. 10: Experimental and analytical structural dynamic results. (Four-percent thick airfoil, pivot at $x / c_{r}=0.65$ ).

\section{Start-up Wing-Clamping Mechanism}

A difficulty that must be dealt with in testing aeroelastic models in the UPWT facility is the large static and dynamic start-up loads that are experienced in forcing the flow to supersonic speeds. The wing-plate structure was designed to survive these loads while the model was constrained near $\alpha=0^{\circ}$. However, in order for the model to attain divergence conditions within the operating envelope of the UPWT facility, the pitch-stiffness elements were built without enough strength to hold the model near $\alpha=0^{\circ}$ during supersonic start-up. To resolve this model shortcoming, a start-up mechanism was designed into the splitter plate apparatus which could be remotely actuated to stiffen the model in the pitch degree of freedom when desired. This mechanism consisted of a bracket that was moved in and out from the splitter plate to disengage or engage, respectively, the wing-plate structure. The bracket was directly connected to a piston in a pneumatic actuator that provide the necessary motion to engage the wing model. This start-up wing-clamping mechanism is shown relative to the total model system in figure 3. Details of the mechanism, located in the splitter plate housing, are shown in figure 8 . The wing-clamping mechanism operated successfully during the wind-tunnel test and successfully performed the task of securing the pivotal motion of the wing during supersonic flow starts (initiation of supersonic flow in the test section) and unstarts (transition from supersonic flow to subsonic flow in the test section).

\section{Divergence Test Procedure}

Supersonic flow was established at the start of each wind-tunnel run at low stagnation pressures and an optimal Mach number to minimize the large static and dynamic start-up loads that are experienced in bringing the flow to supersonic conditions in the UPWT facility. After establishing supersonic flow, test conditions were initially set to a desired Mach number and a dynamic pressure well below the divergence dynamic pressure. Measurements of model subcritical response to windtunnel turbulence were then acquired using the model strain-gauge bridge instrumentation. After acquiring data, the dynamic pressure was incrementally increased while holding the Mach number constant and subcritical response data were acquired for each increment of dynamic pressure. This process was continued until a divergence condition could be extrapolated based on the acquired subcritical response data or until an actual divergence instability occurred.

During the testing, two subcritical response instability-prediction techniques were used. These two techniques were the improved Southwell method and the dynamic frequency method. Both of these methods are discussed in reference 9. The improved Southwell method uses the change in slope of load-versus-angle of attack measurements as dynamic pressure is increased to predict divergence conditions. This method has been successfully demonstrated;9,10 however, accurate predictions were not obtained for this wind-tunnel model using measurements from the strain-gauge bridges on the pitch-stiffness elements. The authors speculate that the proximity of the aerodynamic center to the wing-pitch axis may have led to these poor predictions using this subcritical response technique. Further post-test application of this technique to measurements obtained with the other strain-gauge bridges on the model might provide better results from this prediction technique.

The second prediction method used during the supersonic wind-tunnel test was the dynamic frequency method in which the frequency of the wing-pitch mode was tracked as the dynamic pressure was incrementally increased in the wind tunnel. The concept behind this method is to monitor a model vibrational frequency as it approaches zero at the divergence condition. It is possible with this technique to predict the divergence condition based on an extrapolation of subcritically-measured frequencies. This method was successfully used during the wind-tunnel test to extrapolate divergence dynamic pressures and as guidance in anticipating actual divergence instabilities. 


\section{DIVERGENCE ANALYSES}

Supersonic analyses were conducted using supersonic generalized aerodynamic forces calculated from Van Dyke quasi-steady second-order linear supersonic theory. ${ }^{11}$ This aerodynamic theory is similar to the well-known supersonic aerodynamic formulation called piston theory. ${ }^{12,13}$ Piston theory is generally applicable for Mach numbers greater than 2.0 while the quasi-steady second-order linear supersonic theory gives better pressure results in a range of Mach number around 2.0.14 The supersonic aerodynamic calculations made for the windtunnel models included the effects of wing thickness. Supersonic divergence characteristics were obtained using the P-k stability analysis capability of the STABCAR program. ${ }^{15}$ Figure 11 shows typical variations in modal frequency and damping versus fluid density as predicted with the supersonic analyses tools.
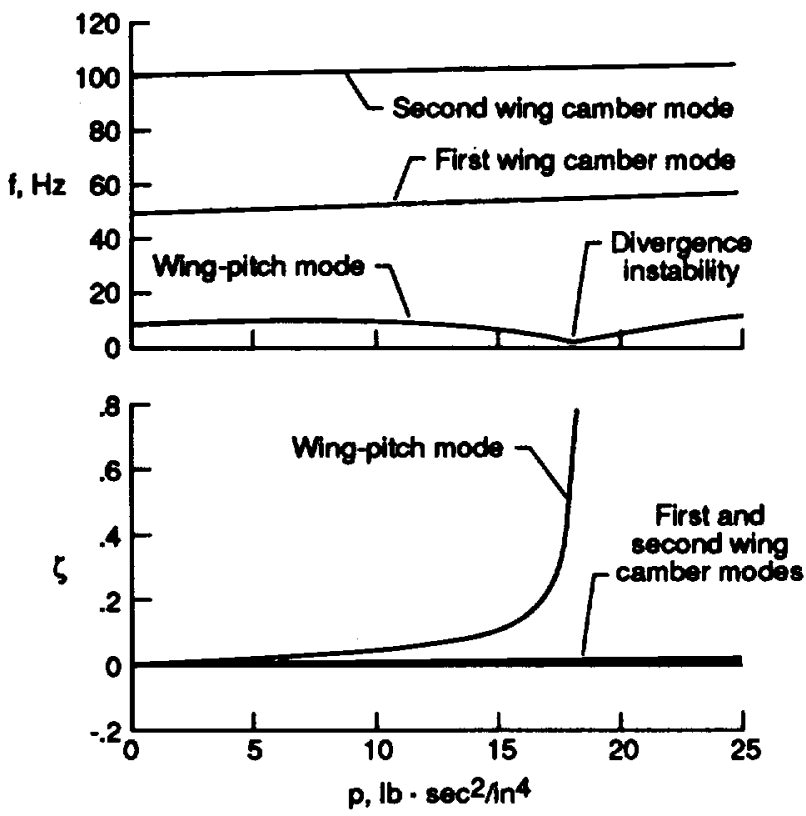

Fig. 11: Typical supersonic aeroelastic solution. Calculations shown for $\mathrm{M}=2.9$, nominal stiffness, four-percent thick airfoil model with pivot at $x / c_{r}=0.65$.

\section{RESULTS AND DISCUSSION}

\section{Analytical Results}

Parametric supersonic aeroelastic analyses were conducted using the four-percent thick airfoil model as the baseline structure. These analyses were conducted for a Mach number range from $M=2.3$ to $M=3.9$. All of the calculations exhibited an increase in divergence dynamic pressure with increases in Mach number as would be anticipated for this Mach number range. Parameters studied were the stiffness of the pitch-stiffness element, the wing-pivot location, and the airfoil thickness. Divergence instability trends determined from these analyses are described in the remainder of this section.

Pitch stiffness effects.- Figure 12 shows the calculated wing divergence boundaries for four different values of pitch stiffness. The results in figure 12 are for the four-percent thick airfoil model with the wing pivot located at $x / c_{1}=0.65$. The divergence boundaries shown in figure 12 are identified by their pitch-stiffness elements in relation to the nominal configuration. The figure clearly shows that increases in stiffness via the pitch-stiffness element result in increases in the divergence dynamic pressure. However, the relative increase in the divergence dynamic pressure becomes less as the pitch-stiffness element becomes stiffer. This is probably due to the inherent flexibility in the wing structure becoming a greater influence on the divergence condition as the pivot pitch stiffness is increased.

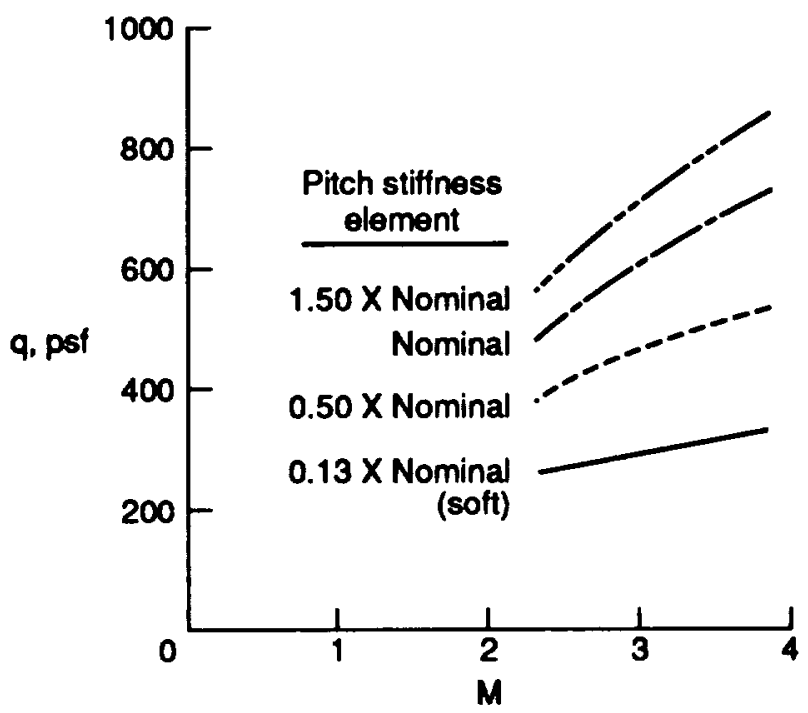

Fig. 12: Calculate effects of pitch stiffness on divergence. (Four-percent thick airfoil, pivot at $x / c_{r}=0.65$ ).

The effect of the wing structure can also be evaluated from another perspective. The stiffness variation between the nominal stiffness and the soft stiffness configurations represents a large change in the pitch-stiffness element (a factor of eight in bending stiffness). A large affect on the divergence phenomenon might be anticipated from this large stiffness change; however, the divergence phenomenon is dependent on the total model stiffness which includes the stiffness of the wing itself exhibited in the wing-pitch mode. The actual calculated change in the divergence boundary between the soft and the nominal stiffness is not a factor of eight, as might be expected if the total stiffness changed by a factor of eight, but only a factor of about two. This indicates that the change of 
total model stiffness is only about two when the stiffness of the pitch-stiffness element is increased by a factor of eight.

Wing-pivot location effects.- Figure 13 shows the calculated effect of wing-pivot location on divergence for the nominal pitch-stiffness element with the four-percent airfoil wing. These calculations exhibit substantial improvements in the divergence dynamic pressure as the wing-pivot location is moved upstream from the $x / c_{1}=$ 0.65 position. At the time of this study, the pivot location for the NASP-vehicle design concept was being planned to be placed between the $x / c_{r}=0.60$ and the $x / c_{r}=$ 0.65 positions. The calculations shown in figure 13 indicate that the supersonic divergence conditions are tremendously dependent on pivot location. The minimum dynamic pressure increase between these two locations is approximately 62 percent for the calculations shown in figure 13. These data indicate that, if a single wing pivot concept is used for a NASP-type vehicle, efforts should be made to place the pivot location significantly forward of the $x / c_{r}=0.65$ position.

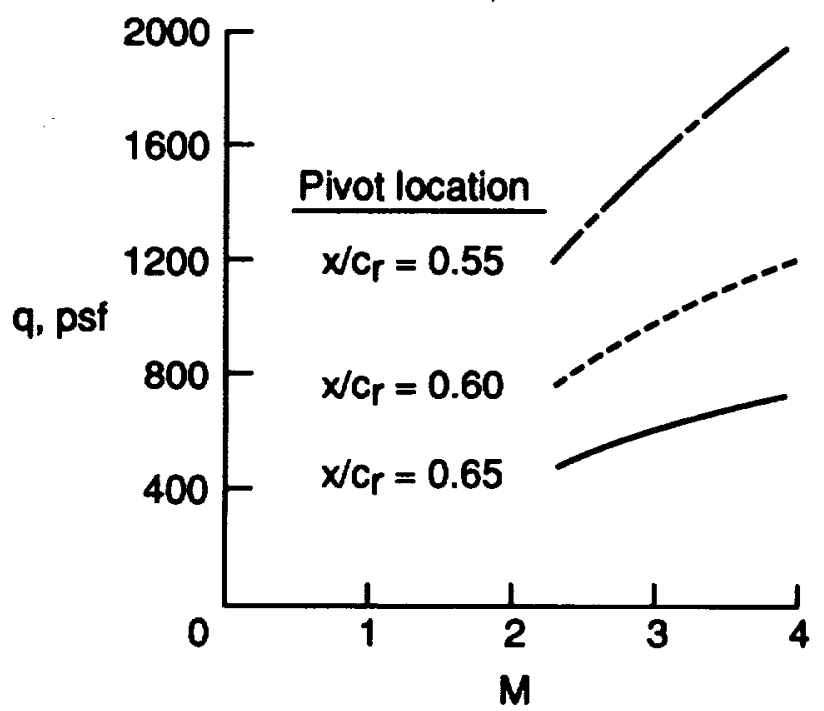

Fig. 13: Calculated pitch-pivot location effects on divergence. (Nominal stiffness, Four-percent thick airfoil).

Airfoil thickness effects.- Figure 14 shows an analytical prediction of the effect of airfoil thickness for the nominal pitch-stiffness element at a wing-pivot location of $x / c_{1}=0.65$. This figure shows that airfoilthickness effects are very important for wing static divergence at supersonic speeds. As indicated in the figure, analyses were conducted for the four-percent and eight-percent thick airfoil models and for a theoretical flatplate configuration. The calculations show that increasing the airfoil thickness is detrimental to the divergence instability conditions. Increasing the airfoil maximum thickness from $t / c=0.04$ to $t / c=0.08$ decreases the divergence dynamic pressure 25 to 37 percent in the Mach number range of 2.3-3.9.

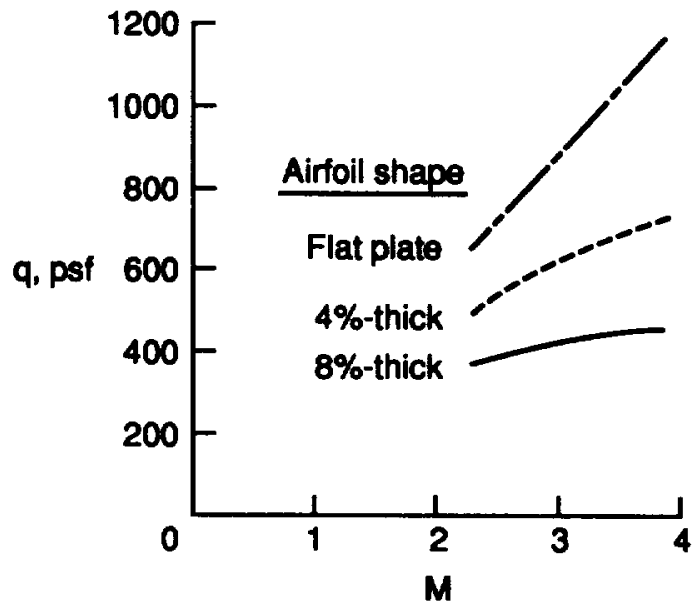

Fig. 14: Calculated airfoil shape effects on divergence. (Nominal stiffness, Four-percent thick airfoil).

\section{Experimental Results}

Experimental testing in the supersonic UPWT facility was accomplished for both the four-percent and the eightpercent airfoil models. The eight-percent thick airfoil model was tested initially and verified that the wingclamping mechanism operated successfully and that the model could survive the supersonic start-up loads in the UPWT test section 2 with the wing-clamping mechanism engaged. During the testing of the eight-percent thick airfoil model, operational procedures for divergence testing in the UPWT were determined and a problem with the model angle-of-attack turntable drive system was resolved. However, an improper bond material was utilized in the fabrication of the eight-percent thick airfoil model and balsa wood was shed before any divergence conditions could be estimated. The damage was such that testing of this model was no longer feasible. Testing of the fourpercent thick airfoil model was then initiated at $\mathbf{M = 2 . 3}$. Unfortunately, further difficulties were experienced in testing at $\mathbf{M = 2 . 3}$ due to large model oscillations and an unexpected test-section transition from supersonic flow to subsonic flow (unstart) which damaged one of the pitchstiffness elements. A significant portion of the test entry was spent trying to test at $\mathrm{M}=\mathbf{2 . 3}$ only to determine that the supersonic flow in the facility was apparently relatively unstable at the low Mach number boundary of the test section (essentially $M=2.3$ ). The remainder of the wind-tunnel test entry was used to test two configurations for the four-percent airfoil model at higher Mach number conditions. These configurations were the nominal and the soft pitch-stiffness element variations with the wing pivot located at $\mathrm{x} / \mathrm{cr}=\mathbf{0 . 6 5}$. Divergence conditions were determined for the nominal stiffness 
configuration at $M=2.6,2.9$, and 3.6. A single divergence condition at $M=2.9$ was determined for the soft stiffness configuration.

Frequency response measurements.- Frequency response measurements were made for each model configuration at every Mach number and dynamic pressure condition tested. Frequencies measured for the wing-pitch mode were evaluated during the testing to estimate the divergence dynamic pressure. Based on analytical results similar to those shown in figure 11, the wing-pivot mode frequency for these NASP-like models was predicted to first increase in frequency as dynamic pressure is increased but eventually, at higher dynamic pressures, the frequency was predicted to decrease. When the analytical frequency decreased to approximately fifty percent of the wind-off natural frequency, the frequency reduction towards the divergence condition occurred rapidly for relatively small increases in dynamic pressure. Figure 15 shows this type of subcritical model response for each of the experimentally determined divergence conditions. The experimental divergence conditions obtained verify that indeed the frequency drops off very rapidly near the divergence instability. In fact, the experimental data show that divergence occurred at dynamic pressures only 3-6 percent beyond the dynamic pressure at which the frequency reaches a value that is fifty percent of the windoff natural frequency. This fact, along with the general trend of the subcritical response frequency data, was used to subcritically predict divergence when it was not desired to obtain actual instabilities.

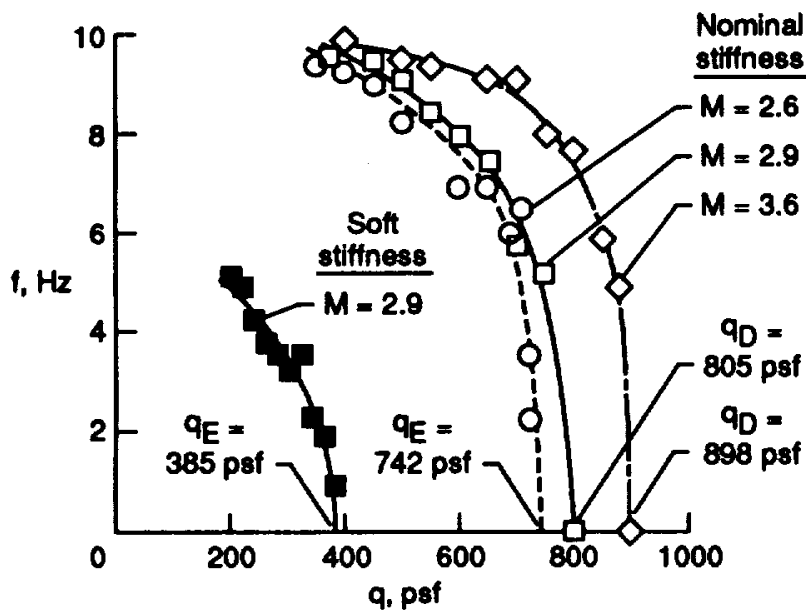

Fig. 15: Subcritical response measurements of wingpitch mode frequencies. (Four-percent thick airfoil, pivot at $x / c_{r}=0.65$ ).

Pitch stiffness effects.- The experimental divergence dynamic pressure conditions obtained for the four-percent thick airfoil model are shown in figure 16 as a function of Mach number. Two divergence conditions were actually obtained for the nominal pitch-stiffness element at $\mathrm{M}=\mathbf{2 . 9}$ and at $M=3.6$. A third divergence condition was extrapolated based on frequency measurements at $\mathrm{M}=2.6$. The analytical predictions for this configuration are also shown in figure 16 as the solid curve. A comparison of the analytical and experimental results for the nominal stiffness configuration shows that the trend of divergence dynamic pressure with Mach number was well predicted but that the absolute magnitudes of the analytical predictions were quite conservative. The analytical results were 23-27 percent conservative based on the experimental data obtained.

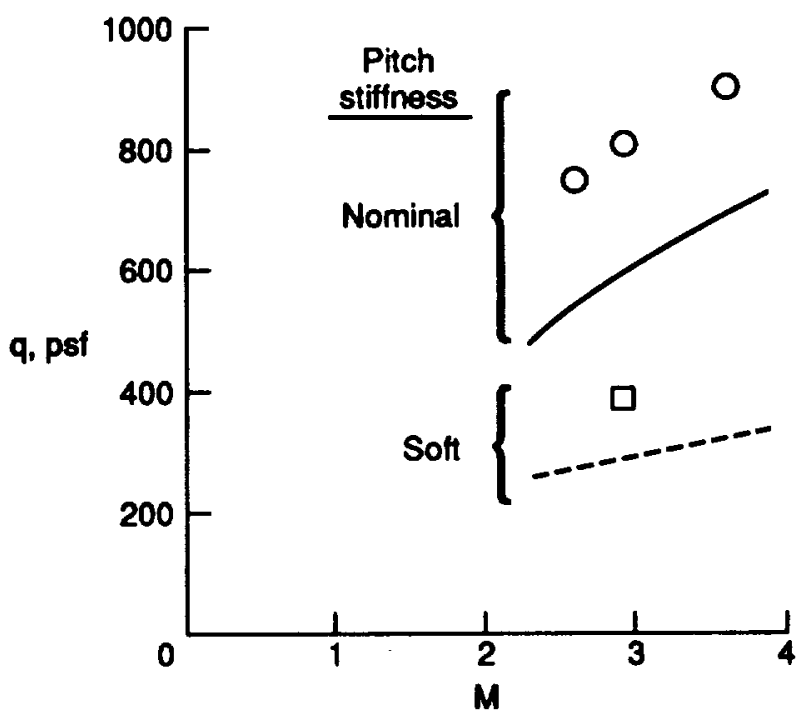

Fig. 16: Experimental and analytical divergence results. (Four-percent thick airfoil, pivot at $x / c_{r}=0.65$ ).

The second experimental configuration for which divergence data was obtained was the soft pitch-stiffness element configuration. Only one divergence condition was estimated, based on subcritical frequency response data, for this configuration at $M=2.9$. This estimated experimental divergence condition and an analytical divergence boundary (dashed curve) are also shown in figure 16. The soft stiffness configuration diverged at approximately 48 percent of the divergence dynamic pressure found for the nominal stiffness configuration at $\mathbf{M}=2.9$. This percentage change in the divergence dynamic pressure corresponds very well with the change analytically predicted for this pitch-stiffness variation. Although the experimental trend with Mach number was not determined for this configuration, the comparison with the analytically-predicted divergence boundary is similar to that determined for the nominal pitch-stiffness element configuration in terms of the magnitudes of dynamic pressure. In this case, the analytical boundary at $\mathbf{M}=\mathbf{2 . 9}$ was 26 percent conservative compared to the experimentally-estimated divergence dynamic pressure. 


\section{CONCLUDING REMARKS}

An experimental study of static wing divergence at supersonic speeds was accomplished for a four-percent maximum thickness airfoil, all-movable wing model with the wing pivoted at the $x / c_{r}=0.65$ location. A nominal and a soft pitch-stiffness element configuration were tested. The nominal pitch-stiffness element had a bending stiffness eight times that of the soft pitch-stiffness element. Divergence conditions were determined for the configuration with the nominal pitch-stiffness element at three Mach numbers from $M=2.6$ to $M=3.6$. One divergence condition was determined for the configuration with the soft pitch-stiffness element at $M=2.9$. The soft pitch-stiffness configuration divergence occurred at approximately 48 percent of the divergence dynamic pressure for the nominal pitch-stiffness configuration at $M=2.9$.

Analytical calculations of divergence were made for correlation with the experimental results and to determine parametric effects of wing-pivot stiffness, wing-pivot location, and airfoil thickness variations. The analytical predictions for the wind-tunnel model configurations tested proved to be 23 to 27 percent conservative based on the experimental divergence dynamic pressure measurements. However, the analyses predicted the trend of the divergence instability with Mach number accurately based on the nominal pitch-stiffness experimental divergence boundary. The parametric analytical studies showed that decreasing airfoil thickness, moving the pitch-pivot location forward along the wing root, or increasing the pitch-pivot stiffness were all beneficial changes because the divergence instability occurred at higher dynamic pressures.

The experimental and analytical results obtained in this study lend themselves strongly to one recommendation for the NASP-vehicle design concept on which these wind-tunnel models were based. If the concept of an all-movable wing is maintained for the NASP vehicle, a thorough evaluation should be made into the possibility of locating the pivot axis as far forward along the wing root as practical. This has the beneficial effect of increasing the divergence dynamic pressure.

\section{REFERENCES}

1) Ricketts, Rodney H.; Cole, Stanley R.; Sandford, Maynard C.; Florance, James R.; Farmer, Moses G.; Spain, Charles V.; Soistmann, David L.; Bullock, Ellen P.; Zeiler, Thomas A.; Pendleton, Ed; and Moster, Greg: Vehicle Flutter Evaluation GWP 71. Paper number 242 from NASP CP 11069, 1992.

2) Rainey, A. Gerald: Aeroelastic Research at High Speeds. NASA TM X-326, 1960.

3) Spain, Charles V.; Zeiler, Thomas A.; Gibbons, Michael D.; Soistmann, David L.; Pozefsky, Peter; DeJesus, Rafael O.; and Brannon, Cyprian P.: Aeroelastic Character of a National Aerospace Plane
Demonstrator Concept. AIAA-93-1314, 1993.

4) Wilkinson, Keith; and Rauch, Frank: Predicted and Measured Divergence Speeds of an Advance Composite Forward Swept Wing Model. AFWALTR-80-3059, 1980.

5) Chipman, Richard; Rauch, Frank; Rimer, Melvyn; Muniz, Benigno; and Ricketts, Rodney H.: Transonic Test of a Forward Swept Wing Configuration Exhibiting Body-freedom Flutter. AIAA-85-0689, 1985.

๑) Rainey, A. Gerald; Hanson, Perry W.; and Martin, Dennis J.: Investigation of the Divergence characteristics of Delta-Planform Canard Controls. NASA TR R-235, 1966.

7) Whetstone, W. D.: EISI-EAL Engineering Analysis Language Reference Manual. Engineering Information Systems, Inc., 1983.

8) Jackson, Charlie M., Jr.; Corlett, William A.; and Monta, William J.: Description and Calibration of the Langley Unitary Plan Wind Tunnel. NASA TP 1905, 1981.

9) Ricketts, R. H.; and Doggett, R. V., Jr.: WindTunnel Experiments on Divergence of Forward-Swept Wings, NASA TP-1685, 1980.

10) Cole, Stanley R.: Divergence Study of a HighAspect-Ratio, Forward-Swept Wing. NASA TM 87682, June, 1986.

11) Van Dyke, Milton D.: A Study of Second-Order Supersonic Flow Theory. NACA Report 1081, 1952.

12) Lighthill, M. J.: Oscillating Airfoils at High Mach Number. Journal of the Aeronautical Sciences, Vol. 20, No. 6, pp. 402-406, June, 1953.

13) Ashley, Holt; and Zartarian, Garabed: Piston Theory--A New Aerodynamic Tool for the Aeroelastician. Journal of the Aeronautical Sciences, Vol. 23, No. 12, pp. 1109-1118, Dec., 1956.

14) Morgan, Homer G.; Huckel, Vera; and Runyan, Harry L.: Procedure for Calculating Flutter at High Supersonic Speed Including Camber Deflections, and Comparison with Experimental Results. NACA TN 4335, 1958.

15) Adams, W. M., Jr., Tiffany, S. H., Newsom, J. R., and Peele, E. L.: STABCAR-A Program for Finding Characteristic Roots of Systems Having Transcendental Stability Matrices. NASA TP-2165, 1984. 


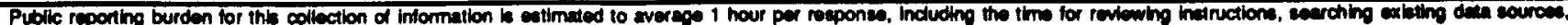

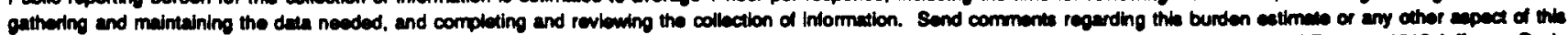

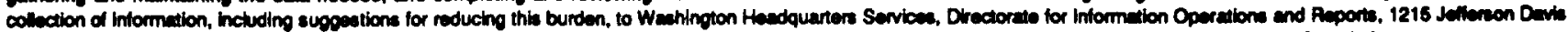

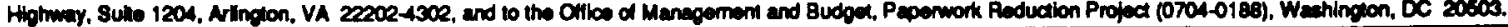

\begin{tabular}{l|l|l|} 
1. AGENCY USE ONLY (LAW blank) & 2. AEPORT DATE & 3. REPOAT TYPE AND DATES COVERED
\end{tabular} April 1993 Technical Memorandum

4. TITLE AND SUBTITLE

Supersonic Aeroelastic Instability Results For A NASP-Like Wing Model 5. FUNDING NUMBERS

Suporsonic Aeroglastic Instability Results For A NASP-Like Wing Modol 763-23-41

6. AUTHOR(S)

Stanley R. Cole, James R. Florance, Lee B. Thomason, Charles V. Spain, and Ellen P. Bullock

7. PEAFORMING OAGANIZATION NAME(S) ANO ADDAESS(ES) NASA Langley Research Center

8. PERFOAMING ORGANIZATION Hampton, Virginia 23681-0001 REPORT MUMBER

9. SPONSORING / MONITOAING AGENCY MAME(S) AND ADDRESS(ES) National Aeronautics and Space Adminstration Washington, DC 20546-0001

10. SPONBORINO / MONTORINO ACENCY REPORT MUMBER

NASA TM-107739

11. SUPPLEMENTARY NOTES Presented at the AIAA 34th SDM Conference, April 19-23, 1993.

Cole, Florance, and Thomason: Langley Research Center, Hampton, VA;

Spain: Lockheed Engineering \& Sciences Co., Hampton, VA;

Bullock: Lockheed Engineering \& Sciences Co., Hampton, VA, now working for U.S. Navy

\begin{tabular}{l|l|}
\hline 12a. DISTRIBUTION/AVAILABILTY STATEMENT & 12b. DISTRIBUTION COOE \\
Unclassified-Unlimited & \\
Subject Category 05 &
\end{tabular}

\section{ABSTRACT (Maximum 200 worda)}

An experimental study and an analytical study have been conducted to examine static divergence for hypersonic-vehicle wing models at supersonic conditions. A supersonic test in the Langley Unitary Plan Wind Tunnel facility was conducted for two wind-tunnel models. These models were nearly identical with the exception of airfoil shape. One model had a four-percent maximum thickness airfoil and the other model had an eight-percent maximum thickness airfoil. The wing models had low-aspect ratios and highly swept leading edges. The all-movable wing models were supported by a single-pivot mechanism along the wing root. For both of the wind-funnel models, configuration changes could be made in the wing-pivot location along the wing root and in the wing-pivot pitch stiffness. Three divergence conditions were measured for the four-percent thick airfoil model in the Mach number range of 2.6 to 3.6 and one divergence condition was measured for the eight-percent thick aifoil model at a Mach number of 2.9. Analytical divergence calculations were made for comparison with experimental results and to evaluate the parametric effects of wing-pivot stiffness, wing-pivot location, and airfoil thickness variations. These analyses showed that decreasing airfoil thickness, moving the wing-pivot location upstream, or increasing the pitch-pivot stiffness have the beneficial effect of increasing the divergence dynamic pressures. The calculations predicted the trend of experimental divergence dynamic pressure with Mach number accurately; however, the calculations were approximately 25 percent conservative with respect to dynamic pressure.

\begin{tabular}{|c|c|c|c|}
\hline \multicolumn{3}{|l|}{ 14. SUBJECT TERMS } & $\begin{array}{l}\text { 15. NUMBEA OF PAGBS } \\
11\end{array}$ \\
\hline $\begin{array}{l}\text { Divergence } \\
\text { Aeroelasticity }\end{array}$ & $\begin{array}{l}\text { National Aero-Space Plane } \\
\text { Supersonic }\end{array}$ & & $\begin{array}{l}\text { 16. PAICE CODE } \\
\text { A03 }\end{array}$ \\
\hline $\begin{array}{l}\text { 17. SECUATY CLASSIFICATION } \\
\text { OF REPORT }\end{array}$ & $\begin{array}{l}\text { 18. SECUATY CLASSIFICATION } \\
\text { OF THIS PAGE }\end{array}$ & $\begin{array}{l}\text { 19. SECUATTY CLASSIFICATION } \\
\text { OF ABSTRACT }\end{array}$ & 20. LMITATION OF ACSTAACT \\
\hline Unclassified & Unclassified & & \\
\hline
\end{tabular}


